\title{
Kombinasi Metode Fuzzy Multiple Attribute Decision Making (FMADM) dan Simple Additive Weighting (SAW) Untuk Menentukan Calon Reviewer Internal Universitas Islam Kuantan Singingi
}

\author{
Febri Haswan*, Helpi Nopriandi \\ Fakultas Teknik, Prodi. Teknik Informatika, Universitas Islam Kuantan Singingi, Teluk Kuantan, Indonesia \\ Email: 1,*febri.haswan88@gmail.com, ${ }^{2}$ helpinopriandi83@gmail.com \\ Email Penulis Korespondensi: febri.haswan88@gmail.com \\ Submitted: 22/12/2021; Accepted: 29/12/2021; Published: 31/12/2021
}

\begin{abstract}
Abstrak-Lembaga Penelitian dan Pengabdian Kepada Masyarakat (LPPM) Universitas Islam Kuantan Singingi setiap tahunnya melakukan penyeleksian calon reviewer internal, yang mana proses penyeleksian yang dilakukan saat ini dengan cara melihat persyaratan calon reviewer yang mendaftar di bagian LPPM, kemuadian persyaratan tersebut nantinya akan di seleksi satu persatu dengan ketentuan yang telah ditetapkan, hasil penilaian yang diperoleh setiap calon nantinya akan di rengkingkan berdasarkan nilai yang tertinggi sampai dengan nilai yang terendah, proses penyeleksian dengan cara tersebut terkadang kurang efektif dan menimbulkan kekeliruan pada saat penilaian, hal tersebut nantinya dapat merugikan peserta yang mencalonkan. Dalam penelitian ini penulis mencoba menerapkan metode FMADM dan SAW yang dapat membantu LPPM dalam penyeleksian calon reviewer internal. Metode Fuzzy Multiple Atribut Decision Making (FMADM) ini nantinya digunakan untuk mencari alternatif dari sejumlah alternatif dengan kriteria tertentu, sedangkan metode Simple Additive Weighting (SAW) digunakan untuk mencari penjumlahan terbobot dari rating kinerja pada setiap alternative dari semua atribut, hasil yang diperoleh dari kedua metode ini nantinya menjumlahkan nilai dari setiap kriteria berdasarkan persyaratan yang dimasukan oleh calon peserta reviewer internal, dari hasil tersebut maka dapat dilihat perolehan nilai yang dimiliki setiap peserta. Hasil inilah nantinya akan dijadikan pertimbangan oleh panitia ataupun pimpinan dalam menentukan reviewer internal di Universitas Islam Kuantan Singingi.
\end{abstract}

Kata Kunci: FMADM; SAW; Kombinasi; Metode; Penerapan

\begin{abstract}
The Institute for Research and Community Service (LPPM) of the Islamic University of Kuantan Singingi annually selects prospective internal reviewers, in which the current selection process is carried out by looking at the requirements for prospective reviewers who register at the LPPM section, then these requirements will be selected one by one. with the provisions that have been set, the results of the assessment obtained by each candidate will be ranked based on the highest value to the lowest value, the selection process in this way is sometimes less effective and causes errors during the assessment, this can later be detrimental to the nominating participants. In this study, the author tries to apply the FMADM and SAW methods which can help LPPM in selecting prospective internal reviewers. This Fuzzy Multiple Attribute Decision Making (FMADM) method will later be used to find alternatives from a number of alternatives with certain criteria, while the Simple Additive Weighting (SAW) method is used to find the weighted summation of the performance ratings on each alternative of all attributes, the results obtained from both This method will add up the scores for each criterion based on the requirements entered by the prospective internal reviewer participants, from these results it can be seen that the score obtained by each participant can be seen. This result will be taken into consideration by the committee or leadership in determining the internal reviewer at the Kuantan Singingi Islamic University.
\end{abstract}

Keywords: FMADM; SAW; Combination; Method; Application

\section{PENDAHULUAN}

Reviewer Proposal adalah seseorang atau sekelompok orang yang memiliki kompetensi yang ditetapkan oleh penyelenggara penelitian untuk menilai kelayakan proposal[1]. Tahapan kerja reviewer ialah menilai proposal sesuai dengan format maupun ketentuan yang telah ditentukan dan mengukur pengusulan dana yang diajukan dalam suatu penelitian maupun pengabdian kepada masyarakat. Melihat pentingnya peran reviewer Lembaga Penelitian dan Pengabdian Kepada Masyarakat (LPPM) Universitas Islam Kuantan Singingi membuka penerimaan calon reviewer internal setiap tahunnya guna meningkatkan kualitas dari suatu penelitian sehingga nantinya penelitian maupun pengabdian kepada masyarakat sesuai apa yang diharapkan. Saat ini proses penyeleksian calon reviewer internal Universitas Islam Kuantan Singingi dilakukan dengan cara melihat persyaratan calon reviewer yang mendaftar di bagian LPPM, kemuadian persyaratan tersebut nantinya akan di seleksi satu persatu dengan ketentuan yang telah ditetapkan, hasil penilaian yang diperoleh setiap calon nantinya akan di rengkingkan berdasarkan nilai yang tertinggi sampai dengan nilai yang terendah, proses penyeleksian dengan cara tersebut terkadang kurang efektif dan menimbulkan kekeliruan pada saat penilaian, hal tersebut nantinya dapat merugikan peserta yang mencalonkan. Dalam penelitian ini penulis mencoba menerapkan sebuah metode FMADM dan SAW dalam penyeleksian calon reviewer internal di Universitas Islam Kuantan Singingi.

Metode Fuzzy Multiple Atribut Decision Making (FMADM) adalah suatu metode untuk mencari alternatif dari sejumlah alternatif dengan kriteria tertentu[2]. Metode FMADM ini menentukan nilai bobot untuk setiap atribut, sedangkan Metode SAW (Simple Additive Weighting) adalah suatu metode yang digunakan untuk mencari alternatif optimal dari sejumlah alternatif dengan kriteria tertentu. Inti dari SAW adalah menentukan nilai bobot untuk setiap atribut, kemudian dilanjutkan dengan proses perolehan nilai tertinggi yang akan menyeleksi alternatif yang sudah diberikan[3]. Dengan dua metode ini nantinya diharapkan dapat membantu LPPM Universitas Islam 
Kuantan Singingi dalam melakukan proses penyeleksian calon reviewer internal sehingga menjadi lebih efektif dan efisien.

\section{METODOLOGI PENELITIAN}

\subsection{Tahapan Penelitian}

Berikut ini adalah alur tahapan penelitian, untuk lebih jelasnya dapat dilihat pada gambar dibawah ini.

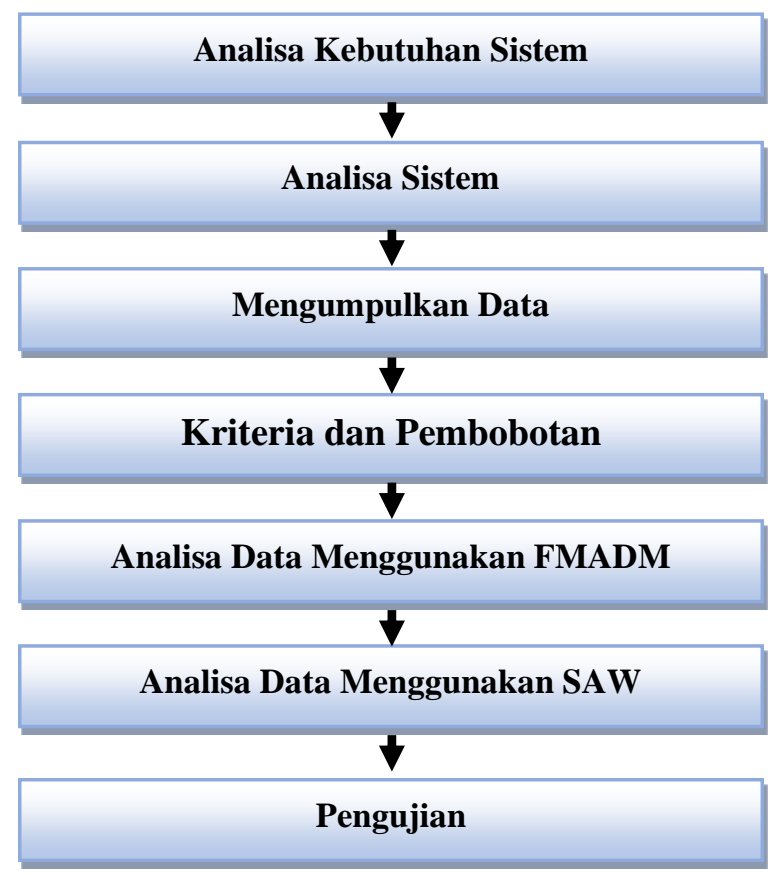

a. Analisis Kebutuhan Sistem

Gambar 1. Tahapan Penelitian

Penelitian ini diawali dengan menganalisis kebutuhan sistem, mempertimbangkan setiap kriteria yang akan digunakan dalam perancangan sistem. Kebutuhan sistem ini berguna untuk menentukan Menentukan Calon Reviewer Internal Universitas Islam Kuantan Singingi.

b. Analisa Sistem

Analisis sistem ini berguna untuk menerapkan Fuzzy Multiple Attribute Decision Making FMADM digunakan untuk mencari alternatif optimalkan dari sejumlah alternatif dengan kriteria tertentu, sedangkan metode Simple additive weighting (SAW) merupakan metode penjumlahan terbobot menghasilkan nilai tertinggi hingga nilai terendah.

c. Mengumpulkan Data

Metode yang digunakan penulis untuk pengumpulan data dengan berbagai metode sebagai berikut :

1. Observasi

Melakukan pengamatan langsung di tempat penelitian untuk mengetahui secara jelas dan terinci permasalahan yang ada. Pengamatan langsung dilalukan pada LPPM Universitas Islam Kuantan Singingi.

2. Interview

Dilakukan untuk memperoleh informasi atau data yang dibutuhkan dengan cara melakukan wawancara langsung pada bagian yang terkait yaitu pada Bagian Penelitian dan Pengabdian Kepada Masyarakat.

3. Studi Literatur

Dalam metode ini informasi dikumpulkan dengan membaca jurnal dan buku - buku yang berhubungan dengan tesis untuk menunjang dalam melakukan analisa terhadap data dan informasi. Diantara buku yang berkaitan dengan Sistem Pendukung Keputusan (SPK), Metode Fuzzy Multiple Attribute Decision Making FMADM dan Metode Simple Additive Weighting (SAW).

d. Kriteria dan Pembobotan

Terdapat 8 (Delapan) kriteria yang akan digunakan dalam Menentukan Calon Reviewer Internal Universitas Islam Kuantan Singingi. Adapun kriteria yang digunakan adalah sebagai berikut :

1. Pendididkan

2. Jabatan Fungsional

3. Penelitian Hibah External

4. Jumlah Publikasi

5. Jumlah Publikasi Terakreditasi 
6. Jumlah Publikasi Terindex Scopus

7. Jumlah HAKI

8. Jumlah Buku

Dari kriteria yang diatas nantinya akan dibobotkan dengan menggunakan menggunakan Fuzzy Multiple Attribute Decision Making (FMADM).

e. Analisa Data Menggunakan FMADM

Analisa data menggunakan Fuzzy Multiple Attribute Decision Making (FMADM) berguna untuk menentukan alternatif-alternatif yang digunakan dalam setiap kriteria, dengan menggunakan Fuzzy Multiple Attribute Decision Making (FMADM) ini nantinya akan didapat beberapa kriteria beserta bobot nilai yang didapat dengan menggunakan Fuzzy Multiple Attribute Decision Making (FMADM).

f. Analisa Data Menggunakan SAW

Pada proses analisa data menggunakan Simple Additive Weighting (SAW) ini berguna untuk menentukan perenkingan tiap peserta yang mengikuti seleksi, dari hasil seleksi yang didapat nantinya akan ditotalkan nilai keseluruhan. Total nilai yang telah dijumlahkan tersebut akan direnkingkan berdasarkan nilai yang tertinggi sampai nilai yang terendah.

g. Pengujian

Pengujian metode ini berguna untuk untuk mengetahui apakah metode tersebut sesuai dengan yang diharapkan.

\section{HASIL DAN PEMBAHASAN}

\subsection{Analisis Kebutuhan Sistem}

Pada proses Menentukan Calon Reviewer Internal Universitas Islam Kuantan Singingi, dibutuhkan suatu kebutuhan sistem untuk mempertimbangkan pada setiap kriteria yang akan digunakan, oleh karena itu ada 8 kriteria yang akan digunakan. Dimana kriteria C1 sampai C8 adalah kriteria keuntungan (Benefit). Adapun kriteria-kriteria tersebut yaitu :

1. $\mathrm{C} 1=$ Pendididkan

2. $\mathrm{C} 2=$ Jabatan Fungsional

3. $\mathrm{C} 3=$ Penelitian Hibah External

4. $\mathrm{C} 4=$ Jumlah Publikasi

5. $\mathrm{C} 5=$ Jumlah Publikasi Terakreditasi

6. $\mathrm{C} 6=$ Jumlah Publikasi Terindex Scopus

7. $\mathrm{C} 7=$ Jumlah HAKI

8. $\mathrm{C} 8=$ Jumlah Buku

\subsection{Penetapan Input}

Untuk penetapan input pada penentuan Reviewer Internal Universitas Islam Kuantan Singingi maka digunakan variabel sebagai berikut :

1. Variabel $\mathrm{C} 1=$ Pendididkan

2. Variabel $\mathrm{C} 2=$ Jabatan Fungsional

3. Variabel C3 = Penelitian Hibah External

4. Variabel $\mathrm{C} 4=$ Jumlah Publikasi

5. Variabel C5 = Jumlah Publikasi Terakreditasi

6. Variabel C6 = Jumlah Publikasi Terindex Scopus

7. Variabel C7 = Jumlah HAKI

8. Variabel C8 = Jumlah Buku

Dari tiap-tiap variabel ini nantinya akan memiliki nilai bobot yang telah ditentukan dengan menggunakan Fuzzy Multiple Attribute Decision Making (FMADM), oleh karena itu maka dibuat suatu variabel yang akan diubah ke dalam bilangan Fuzzy dengan rumus:

$$
\text { variabel ke-n/(n-1) }
$$

Keterangan : $\mathrm{n}=$ nilai bobot

$$
\mathrm{n}-1 \text { = jumlah variabel-1 }
$$

\subsection{Kriteria dan Pembobotan}

Terdapat 8 (Delapan) kriteria yang akan digunakan dalam Menentukan Reviewer Internal Universitas Islam Kuantan Singingi. Adapun kriteria dan bilangan fuzzy yang digunakan dalam Menentukan Reviewer Internal Universitas Islam Kuantan Singingi sebagai berikut:

a. Kriteria Pendidikan : 
Tabel 1. Kriteria Pendidikan

\begin{tabular}{cc}
\hline Pendidikan & Bobot (Nilai) \\
\hline- & Variabel ke $-0 /(3-1)=0$ \\
S2 & Variabel ke $-1 /(3-1)=0,5$ \\
S3 & Variabel ke $-2 /(3-1)=1$ \\
\hline
\end{tabular}

b. Kriteria Jabatan Fungsional :

Tabel 2. Jabatan Fungsional

\begin{tabular}{cc}
\hline Jabatan Fungsional & Bobot (Nilai) \\
\hline Belum Ada & Variabel ke $-0 /(5-1)=0$ \\
Asisten Ahli & Variabel ke $-1 /(5-1)=0,25$ \\
Lektor & Variabel ke $-2 /(5-1)=0,5$ \\
Lektor Kepala & Variabel ke $-3 /(5-1)=0,75$ \\
Guru Besar & Variabel ke $-4 /(5-1)=1$ \\
\hline
\end{tabular}

c. Kriteria Jumlah Penelitian Hibah External :

Tabel 3. Kriteria Jumlah Penelitian Hibah External

\begin{tabular}{cc}
\hline $\begin{array}{c}\text { Jumlah Penelitian } \\
\text { Hibah External }\end{array}$ & Bobot (Nilai) \\
\hline 0 & Variabel ke $-0 /(6-1)=0$ \\
$1-2$ & Variabel ke $-1 /(6-1)=0,2$ \\
$3-4$ & Variabel ke $-2 /(6-1)=0,4$ \\
$5-6$ & Variabel ke $-3 /(6-1)=0,6$ \\
$7-8$ & Variabel ke $-4 /(6-1)=0,8$ \\
$9-10$ & Variabel ke $-5 /(6-1)=1$ \\
\hline
\end{tabular}

d. Kriteria Jumlah Publikasi :

Tabel 4. Jumlah Publikasi

\begin{tabular}{cc}
\hline Jumlah Publikasi & Bobot (Nilai) \\
\hline 0 & Variabel ke $-0 /(7-1)=0$ \\
$1-5$ & Variabel ke $-1 /(7-1)=0,16$ \\
$6-10$ & Variabel ke $-2 /(7-1)=0,33$ \\
$11-15$ & Variabel ke $-3 /(7-1)=0,5$ \\
$16-20$ & Variabel ke $-4 /(7-1)=0,66$ \\
$21-25$ & Variabel ke $-5 /(7-1)=0,83$ \\
$26-30$ & Variabel ke $-6 /(7-1)=1$ \\
\hline
\end{tabular}

e. Kriteria Jumlah Publikasi Terakreditasi :

Tabel 5. Jumlah Publikasi Terakreditasi

\begin{tabular}{cc}
\hline $\begin{array}{c}\text { Jumlah Publikasi } \\
\text { Terakreditasi }\end{array}$ & Bobot (Nilai) \\
\hline 0 & Variabel ke $-0 /(11-1)=0$ \\
$1-2$ & Variabel ke $-1 /(11-1)=0,1$ \\
$3-4$ & Variabel ke $-2 /(11-1)=0,2$ \\
$5-6$ & Variabel ke $-3 /(11-1)=0,3$ \\
$7-8$ & Variabel ke $-4 /(11-1)=0,4$ \\
$9-10$ & Variabel ke $-5 /(11-1)=0,5$ \\
$11-12$ & Variabel ke $-6 /(11-1)=0,6$ \\
$13-14$ & Variabel ke $-7 /(11-1)=0,7$ \\
$15-16$ & Variabel ke $-8 /(11-1)=0,8$ \\
$17-18$ & Variabel ke $-9 /(11-1)=0,9$ \\
$19-20$ & Variabel ke $-10 /(11-1)=1$ \\
\hline
\end{tabular}

f. Kriteria Jumlah Publikasi Terindex Scopus: 
Tabel 6. Jumlah Publikasi Terindex Scopus

\begin{tabular}{cc}
\hline $\begin{array}{c}\text { Jumlah Publikasi } \\
\text { Terindex Scopus }\end{array}$ & Bobot (Nilai) \\
\hline 0 & Variabel ke $-0 /(11-1)=0$ \\
$1-2$ & Variabel ke $-1 /(11-1)=0,1$ \\
$3-4$ & Variabel ke $-2 /(11-1)=0,2$ \\
$5-6$ & Variabel ke $-3 /(11-1)=0,3$ \\
$7-8$ & Variabel ke $-4 /(11-1)=0,4$ \\
$9-10$ & Variabel ke $-5 /(11-1)=0,5$ \\
$11-12$ & Variabel ke $-6 /(11-1)=0,6$ \\
$13-14$ & Variabel ke $-7 /(11-1)=0,7$ \\
$15-16$ & Variabel ke $-8 /(11-1)=0,8$ \\
$17-18$ & Variabel ke $-9 /(11-1)=0,9$ \\
$19-20$ & Variabel ke $-10 /(11-1)=1$ \\
\hline
\end{tabular}

g. Kriteria Jumlah HAKI:

Tabel 7. Jumlah HAKI

\begin{tabular}{cc}
\hline Jumlah HAKI & Bobot (Nilai) \\
\hline 0 & Variabel ke $-0 /(6-1)=0$ \\
$1-2$ & Variabel ke $-1 /(6-1)=0,2$ \\
$3-4$ & Variabel ke $-2 /(6-1)=0,4$ \\
$5-6$ & Variabel ke $-3 /(6-1)=0,6$ \\
$7-8$ & Variabel ke $-4 /(6-1)=0,8$ \\
$9-10$ & Variabel ke $-5 /(6-1)=1$ \\
\hline
\end{tabular}

h. Kriteria Jumlah Buku:

Tabel 8. Jumlah Buku

\begin{tabular}{cc}
\hline Jumlah Buku & Bobot (Nilai) \\
\hline 0 & Variabel ke $-0 /(6-1)=0$ \\
$1-2$ & Variabel ke $-1 /(6-1)=0,2$ \\
$3-4$ & Variabel ke $-2 /(6-1)=0,4$ \\
$5-6$ & Variabel ke $-3 /(6-1)=0,6$ \\
$7-8$ & Variabel ke $-4 /(6-1)=0,8$ \\
$9-10$ & Variabel ke $-5 /(6-1)=1$ \\
\hline
\end{tabular}

\subsection{Pembahasan dan Hasil}

Pada sub bab ini akan dibahas tentang proses perhitungan dan keluaran pada penelitian ini.

1. Menentukan kriteria-kriteria yang akan dijadikan acuan dalam pengambilan keputusan yaitu $\mathrm{C} 1$ sampai dengan C8.

2. Menentukan rating kecocokan setiap alternatif. Dapat dilihat pada tabel 4.1 sampai dengan tabel 4.8.

3. Membuat matrik keputusan berdasarkan kriteria $\left(C_{i}\right)$, kemudian melakukan normalisasi matrik berdasarkan persamaan yang disesuaikan dengan jenis atribut (Atribut keuntungan atau atribut biaya) sehingga diperoleh matrik ternormalisasi.

Analisa pembahasan dan hasil penggunaan agoritma FMDAM digunakan untuk menentukan nilai bobot pada setiap kriteria dalam menentukan Calon Reviewer Internal Universitas Islam Kuantan Singingi setelah bobot nilai diperoleh kemudian data Calon Reviewer akan di conversikan berdasarkan pesyaratan calon, kemudian untuk Memenuhi Persyaratan atau Tidak maka digunakan metode SAW. Hasil yang akan diperoleh dengan mencari peringkat/perangkingan dari setiap calon. Untuk contoh kasus yang diambil yaitu pada tabel 9.

Tabel 9. Calon Reviewer

\begin{tabular}{cccccccccc}
\hline No. & $\begin{array}{c}\text { Calon } \\
\text { Reviewer }\end{array}$ & C1 & C2 & C3 & C4 & C5 & C6 & C7 & C8 \\
\hline 1. & Calon 1 & S2 & Lektor & 0 & $6-10$ & $3-4$ & 0 & $1-2$ & $1-2$ \\
2. & Calon 2 & S3 & Lektor & $1-2$ & $11-15$ & $5-6$ & 0 & $1-2$ & $1-2$ \\
3. & Calon 3 & S2 & Lektor & $1-2$ & $11-15$ & $7-8$ & $1-2$ & $3-4$ & $3-4$ \\
\hline
\end{tabular}

Tabel 9. di atas menerangkan bahwa Calon Reviewer yang telah melaksanakan berbagai seleksi akan direngkingkan berdasarkan 8 kriteria yang telah ditentukan dengan nilai sebelumnya telah dibuat ke bilangan fuzzy. 
Data Calon Reviewer diatas, akan dikonversikan ke dalam fuzzy yang sudah ditentukan pada pembahasan sebelumnya :

Tabel 10. Calon Reviewer dengan Bilai Fuzzy

\begin{tabular}{cccccccccc}
\hline \multirow{2}{*}{ No. } & Calon & \multicolumn{9}{c}{ Criteria } \\
& Reviewer & C1 & C2 & C3 & C4 & C5 & C6 & C7 & C8 \\
\hline 1. & Calon 1 & 0,5 & 0,5 & 0 & 0,33 & 0,2 & 0 & 0,2 & 0,2 \\
2. & Calon 2 & 1 & 0,5 & 0,2 & 0,5 & 0,3 & 0 & 0,2 & 0,2 \\
3. & Calon 3 & 0,5 & 0,5 & 0,2 & 0,5 & 0,4 & 0,1 & 0,4 & 0,4 \\
\hline
\end{tabular}

Tabel 10. diatas menyatakan semua nilai Calon Reviewer yang nantinya akan dijumlahkan dari C1, C2, C3, C4, C5, C6, C7, dan C8 sehingga nantinya akan mendapatkan suatu nilai dengan bilangan fuzzy. Selanjunya akan dilanjutkan pada langkah yang ketiga yaitu : Membuat matriks keputusan berdasarkan kriteria $\mathrm{C}_{i}$, kemudian melakukan normalisasi matriks berdasarkan persamaan yang disesuaikan dengan jenis atribut sehingga diperoleh matriks ternormalisasi R. Berdasarkan pada tabel 10. diatas, dapat dibentuk matrik keputusan X dengan menggunakan rumus (1) data berikut :

$$
X=\left(\begin{array}{llllllll}
0,5 & 0,5 & 0 & 0,33 & 0,2 & 0 & 0,2 & 0,2 \\
1 & 0,5 & 0,2 & 0,5 & 0,3 & 0 & 0,2 & 0,2 \\
0,5 & 0,5 & 0,2 & 0,5 & 0,4 & 0,1 & 0,4 & 0,4
\end{array}\right)
$$

Untuk mendapatkan matrik ternormalisasi yaitu dengan menggunakan rumus (1) :

A. Normalisasi untuk Kriteria (C1) Pendidikan

$$
\begin{aligned}
& \mathrm{R} 11=\frac{0,5}{\operatorname{Max}\{0,5 ; 1 ; 0,5\}}=\frac{0,5}{1}=0,5 \\
& \mathrm{R} 12=\frac{1}{\operatorname{Max}\{0,5 ; 1 ; 0,5\}}=\frac{1}{1}=1 \\
& \mathrm{R} 13=\frac{0,5}{\operatorname{Max}\{0,5 ; 1 ; 0,5\}}=\frac{0,5}{1}=0,5
\end{aligned}
$$

B. Normalisasi untuk Kriteria (C2) Jabatan Fungsional

$$
\begin{aligned}
& \mathrm{R} 21=\frac{0,5}{\operatorname{Max}\{0,5 ; 0,5 ; 0,5\}}=\frac{0,5}{0,5}=1 \\
& \mathrm{R} 22=\frac{0,5}{\operatorname{Max}\{0,5 ; 0,5 ; 0,5\}}=\frac{0,5}{0,5}=1 \\
& \mathrm{R} 23=\frac{0,5}{\operatorname{Max}\{0,5 ; 0,5 ; 0,5\}}=\frac{0,5}{0,5}=1
\end{aligned}
$$

C. Normalisasi untuk Kriteria (C3) Penelitian Hibah External

$$
\begin{aligned}
& \mathrm{R} 31=\frac{0}{\operatorname{Max}\{0 ; 0,2 ; 0,2\}}=\frac{0}{0,2}=0 \\
& \mathrm{R} 32=\frac{0,2}{\operatorname{Max}\{0 ; 0,2 ; 0,2\}}=\frac{0,2}{0,2}=1 \\
& \mathrm{R} 33=\frac{0,2}{0,2}=1
\end{aligned}
$$


ISSN 2684-8910 (media cetak)

ISSN 2685-3310 (media online)

DOI 10.47065/bits.v3i3.1136

$$
\operatorname{Max}\{0 ; 0,2 ; 0,2\} \quad 0,2
$$

D. Normalisasi untuk Kriteria (C4) Jumlah Publikasi

$$
\begin{aligned}
& \mathrm{R} 41=\frac{0,33}{\operatorname{Max}\{0,33 ; 0,5 ; 0,5\}}=\frac{0,33}{0,5}=0,66 \\
& \mathrm{R} 42=\frac{0,5}{\operatorname{Max}\{0,33 ; 0,5 ; 0,5\}}=\frac{0,5}{0,5}=1 \\
& \mathrm{R} 43=\frac{0,5}{\operatorname{Max}\{0,33 ; 0,5 ; 0,5\}}=\frac{0,5}{0,5}=1
\end{aligned}
$$

E. Normalisasi untuk Kriteria (C5) Jumlah Publikasi Terakreditasi

$$
\begin{aligned}
& \mathrm{R} 51=\frac{0,2}{\operatorname{Max}\{0,2 ; 0,3 ; 0,4\}}=\frac{0,2}{0,4}=0,5 \\
& \mathrm{R} 52=\frac{0,3}{\operatorname{Max}\{0,2 ; 0,3 ; 0,4\}}=\frac{0,3}{0,4}=0,75 \\
& \mathrm{R} 53=\frac{0,4}{\operatorname{Max}\{0,2 ; 0,3 ; 0,4\}}=\frac{0,4}{0,4}=1
\end{aligned}
$$

F. Normalisasi untuk Kriteria (C6) Jumlah Publikasi Terindex Scopus

$$
\begin{aligned}
& \mathrm{R} 61=\frac{0}{\operatorname{Max}\{0 ; 0 ; 1\}}=\frac{0}{1}=0 \\
& \mathrm{R} 62=\frac{0}{\operatorname{Max}\{0 ; 0 ; 1\}}=\frac{0}{1}=0 \\
& \mathrm{R} 63=\frac{1}{\operatorname{Max}\{0 ; 0 ; 1\}}=\frac{1}{1}=1
\end{aligned}
$$

G. Normalisasi untuk Kriteria (C7) Jumlah HAKI

$$
\begin{aligned}
& \mathrm{R} 71=\frac{0,2}{\operatorname{Max}\{0,2 ; 0,2 ; 0,4\}}=\frac{0,2}{0,4}=0,5 \\
& \mathrm{R} 72=\frac{0,2}{\operatorname{Max}\{0,2 ; 0,2 ; 0,4\}}=\frac{0,2}{0,4}=0,5 \\
& \mathrm{R} 73=\frac{0,4}{\operatorname{Max}\{0,2 ; 0,2 ; 0,4\}}=\frac{0,4}{0,4}=1
\end{aligned}
$$

H. Normalisasi untuk Kriteria (C8) Jumlah Buku

$$
0,2 \quad 0,2
$$




$$
\begin{aligned}
& \mathrm{R} 81=\frac{0.2}{\operatorname{Max}\{0,2 ; 0,2 ; 0,4\}}=\frac{0,4}{2}=0,5 \\
& \mathrm{R} 82=\frac{0,2}{\operatorname{Max}\{0,2 ; 0,2 ; 0,4\}}=0,5 \\
& \mathrm{R} 83=\frac{0,4}{\operatorname{Max}\{0,2 ; 0,2 ; 0,4\}}=\frac{0,4}{0,4}=1
\end{aligned}
$$

Berdasarkan hasil perhitungan normalisasi matriks $\mathrm{X}$, maka dapat ditentukan matriks ternormalisasi $\mathrm{R}$ sebagai berikut :

$$
\mathrm{R}=\left(\begin{array}{llllllll}
0.5 & 1 & 0 & 0,66 & 0,5 & 0 & 0,5 & 0,5 \\
1 & 1 & 1 & 1 & 0,75 & 0 & 0,5 & 0,5 \\
0,5 & 1 & 1 & 1 & 1 & 1 & 1 & 1
\end{array}\right)
$$

Dari kriteria yang telah ditentukan, maka dibuat suatu tingkat kepentingan kriteria berdasarkan nilai bobot yang telah ditentukan ke dalam bilangan fuzzy dengan rumus yaitu variabel ke-n/n-1. Ranting kecocokan setiap alternatif pada setiap kriteria sebagai berikut :

Tabel 11. Tingkat Kepentingan Setiap Kriteria

\begin{tabular}{lcc}
\hline \multicolumn{1}{c}{ Kriteria } & \multicolumn{1}{c}{ Variabel } & Bobot \\
\hline C1 = Pendididkan & Sangat Penting (CP) & 1 \\
C2 = Jabatan Fungsional & Sangat Penting (CP) & 1 \\
C3 = Penelitian Hibah External & Penting (SP) & 0,5 \\
C4 = Jumlah Publikasi & Sangat Penting (SP) & 1 \\
C5 = Jumlah Publikasi Terakreditasi & Penting (SP) & 0,5 \\
C6 = Jumlah Publikasi Terindex Scopus & Sangat Penting (SP) & 1 \\
C7 = Jumlah HAKI & Sangat Penting (SP) & 1 \\
C8 = Jumlah Buku & Sangat Penting (SP) & 1 \\
\hline
\end{tabular}

Dari tabel 11, 6 kriteria yang ada diberi bobot dengan mengubahnya ke bilangan fuzzy yaitu adalah :

$$
\mathrm{W}=\left[\begin{array}{llllllll}
1 & 1 & 0,5 & 1 & 0,5 & 1 & 1 & 1
\end{array}\right]
$$

Kemudian tahap terakhir untuk mendapatkan proses perangkingan yaitu dengan cara mengalihkan bobot (W) dengan matrik yang telah ternormalisasi $(\mathrm{R})$ seperti yang ada dibawah ini :

$$
\begin{aligned}
\mathrm{V} 1 & =(0,5)(1)+(1)(1)+(0)(0,5)+(0,66)(1)+(0,5)(0,5)+(0)(1)+(0,5)(1)+(0,5)(1) \\
& =0,5+1+0+0,66+0,5+0+0,5+0,5 \\
& =3,66 \\
\mathrm{~V} 2 & =(1)(1)+(1)(1)+(1)(0,5)+(1)(1)+(0,75)(0,5)+(0)(1)+(0,5)(1)+(0,5)(1) \\
& =1+1+0,5+1+0,375+0+0,5+0,5 \\
& =4,875 \\
\mathrm{~V} 3 \quad & =(0,5)(1)+(1)(1)+(1)(0,5)+(1)(1)+(1)(0,5)+(1)(1)+(1)(1)+(1)(1) \\
& =0,5+1+0,5+1+0,5+1+1+1 \\
& =6,5
\end{aligned}
$$

Kesemua nilai peringkat V1-V3 dari hasil perkalian dengan normalisasi digabungkan dalam tabel 4.12, sehingga diperoleh hasil perangkingan pada tabel dibawah ini :

Tabel 12. Total Nilai Keseluruhan

\begin{tabular}{ccc}
\hline No & Calon Revewer & Hasil \\
\hline 1. & Calon 1 & 3,66 \\
2. & Calon 2 & 4,875 \\
3. & Calon 3 & 6,5 \\
\hline
\end{tabular}


Tabel 13. Hasil Perankingan

\begin{tabular}{|c|c|c|c|c|c|c|c|c|c|c|c|}
\hline No. & $\begin{array}{c}\text { Calon } \\
\text { Reviewer }\end{array}$ & $\mathrm{C} 1$ & $\mathrm{C} 2$ & C3 & $\begin{array}{l}\text { Criteria } \\
\text { C4 }\end{array}$ & C5 & C6 & C7 & $\mathrm{C} 8$ & Hasil & Ranking \\
\hline 1. & Calon 3 & 0,5 & 0,5 & 0,2 & 0,5 & 0,4 & 0,1 & 0,4 & 0,4 & 6,5 & 1 \\
\hline 2. & Calon 2 & 1 & 0,5 & 0,2 & 0,5 & 0,3 & 0 & 0,2 & 0,2 & 4,875 & 2 \\
\hline 3. & Calon 1 & 0,5 & 0,5 & 0 & 0,33 & 0,2 & 0 & 0,2 & 0,2 & 3,66 & 3 \\
\hline
\end{tabular}

\section{KESIMPULAN}

Setelah dilakukan analisis dan pengujian untuk menentukan Calon Reviewer Internal Universitas Islam Kuantan Singingi dengan menggunakan Fuzzy Multiple Attribute Decision Making (FMADM) dan metode Simple Additive Weighting (SAW) maka dapat diambil kesimpulan bahwa Metode Fuzzy Multiple Attribute Decision Making (FMADM) dapat membantu dalam mentukan bobot nilai di setiap kriteria dalam penyeleksian Calon Reviewer Internal Universitas Islam Kuantan Singingi, sedangkan penerapan Metode Simple Additive Weighting (SAW) memudahkan penjumlahan nilai bobot disetiap kriteria berdasarkan persyaratan dan ketentuan bobot nilai yang telah ditentukan. Dengan menerapkan dua metode tersebut dapat memilih alternatif terbaik dari beberapa alternatif dengan menggunakan setiap kriteria.

\section{REFERENCES}

[1] K. Riset, "Pelatihan reviewer penelitian nasional," 2017.

[2] F. Haswan, "Decision Support System For Election Of Members Unit Patients Pamong Praja," Int. J. Artif. Intell. Res., vol. 1, no. 1, p. 21, 2017, doi: 10.29099/ijair.v1i1.14.

[3] Lismardiana, "Fuzzy Multi-Atribute Decision Making (Fuzzy Madm) Dengan Metode Saw Dalam Penentuan Lulusan Mahasiswa Berprestasi," J. Teknol. Inf. Dan Komun., vol. 7, no. 1, pp. 37-46, 2018.

[4] Nopriandi, H., \& Al Hafiz, N. W. (2019). Sistem Pendukung Keputusan Pemilihan Dosen Berprestasi Di Lingkungan Fakultas Tarbiyah Dan Keguruan Menggunakan Fuzzy Multiple Attribut Decision Making (FMADM). Jurnal Teknologi Dan Open Source, 2(2), 33-44.

[5] Asep, H., R., dan Dini, D., dan Andri, I. (2012). "Sisten Pendukung Keputusan Penyeleksian Calon Siswa Baru Di SMA Negeri 3 Garut" Jurnal Algoritma Sekolah Tinggi Garut Volume 09, Nomor 21 (2012), ISSN 2302 - 7339.

[6] Jogiyanto. (2009). "Sistem Teknologi Informasi” Edisi III, Andi. Yogyakarta

[7] Nandang, H. (2012). "Sistem Pendukung Keputusan Menggunakan Metode Simple Additive Weighting (SAW) Untuk Menentukan Jurusan Pada SMK Bakti Purworkerto" Seminar Nasiona Teknologi Informasi dan Komunikasi Terapan Semarang, 23 Juni 2012, ISBN $979-26-0255-0$.

[8] Nurdin, B., dan Helmie, A., W., dan Sukmawati, N., E., dan Sutiko. (2012). "Sistem Pendukung Keputusan, Komputasi dan Simulasi” Seminar Nasional Ilmu Komputer Universitas Diponegoro, 15 September 2012, ISBN 978 - 979 - 756 - 843 6.

[9] Sri, E. (2011). "Perancangan Sistem Pendukung Pengambilan Keputusan Untuk Penerimaan Beasiswa Dengan Metode SAW (Simple Additive Weighting)" Jurnal Teknologi Informasi DINAMIK Volume 16, Nomor 2 (2011) Halaman 171-176, ISSN 0854 - 9524.

[10] Sugiyono, dan Nazori, A. (2012). "Model Peta Digital Rawan Sambaran Petir Dengan Menggunakan Metode SAW (Simple Additive Weighting)" Jurnal Telematika M.Kom Volume 4, Nomor 1 (2012), ISSN 2085 - 725X.

[11] Harnaningrum, L. N. (2002). Rekayasa Perangkat Lunak. Yogyakarta: Andi.

[12] Janko, W., \& Bernoider, E. (2005). Multi-Criteria Decision Making An Application Study of ELECTRE \& TOPSIS. Yogyakarta: Graha Ilmu.

[13] Kadir, A. (2003). Pengenalan Sistem Informasi. Yogyakarta: Andi.

[14] Rudianto, A. M. (2011). Pemrograman Web Dinamis menggunakan PHP dan MySQL. Yogyakarta: Andi. 